\title{
Perencanaan Angkutan Feeder Yang Melayani Brt Koridor 2 (Nusadua-Bandara)
}

\author{
I Made suraharta, Adelin Feblika Ananda, Dessy Angga A \\ Politeknik Transportasi Darat Indonesia-STTD \\ Email: isuraharta@ptdisttd.ac.id
}

\begin{abstract}
Abstrak
Tujuan penelitian ini adalah menganalisis perencanaan angkutan feeder yang melayani BRT Koridor 2 (Nusadua-Bandara). Penelitian ini menggunakan jenis penelitian kualitatif dengan pendekatan analisis deskriptif. Data dalam penelitian ini berjenis data primer dan data sekunder. Metode analisis data dalam penelitian ini menggunakan metode analisis permintaan, analisis pemilihan rute, analisis armada, dan analisis BOK. Berdasarkan analisis data dalam penelitian, maka dapat disimpulkan bahwa: 1) Berdasarkan hasil survei wawancara, diketahui bahwa jumlah permintaan untuk angkutan feeder adalah 66 responden untuk permintaan aktual dan 458 untuk permintaan potensial. Pergerakan yang ditimbulkan oleh responden yang paling tinggi berasal dari zona 6 , dimana tata guna lahan pada zona tersebut merupakan kawasan wisata dan pusat pendidikan; 2) Rute rencana untuk pengoperasian angkutan feeder di Kuta Selatan dibagi menjadi 3 rute dengan pelayanan rute yang berbeda; 3) Jumlah armada yang dibutuhkan pada tiap rute: Permintaan Potensial yaitu: a) Rute 1 jumlah kebutuhan armada 2 kendaraan, b) Rute 2 jumlah kebutuhan armada 1 kendaraan, dan c) Rute 3 jumlah kebutuhan armada 4 kendaraan; dan 4) Tarif usulan yang sesuai untuk angkutan feeder: a) Rute 1 dengan tarif sebesar Rp. 5.500,-; b) Rute 2 dengan tarif sebesar Rp. 4.000,-; dan c) Rute 3 dengan tarif sebesar Rp. 7.000,-.
\end{abstract}

Kata Kunci: Perencaan, Angkutan Feeder, Analisis.

\begin{abstract}
The purpose of this study was to analyze the planning of feeder transport serving BRT Corridor 2 (Nusadua-Airport). This research uses qualitative research with descriptive analysis approach. The data in this study are primary data and secondary data. The data analysis method in this study uses the demand analysis method, route selection analysis, fleet analysis, and BOK analysis. Based on the analysis of the data in the study, it can be concluded that: 1) Based on the results of the interview survey, it is known that the number of requests for feeder transportation is 66 respondents for actual demand and 458 for potential demand. The movement caused by the highest respondents came from zone 6 , where the land use in the zone is a tourist area and an education center; 2) The planned route for the operation of feeder transport in South Kuta is divided into 3 routes with different service routes; 3) The number of fleets needed on each route: Potential Demand, namely: a) Route 1 total needs for a fleet of 2 vehicles, b) Route 2 requires a fleet of 1 vehicle, and c) Route 3 requires a fleet of 4 vehicles; and 4) Appropriate proposed tariffs for feeder transport: a) Route 1 with a tariff of IDR. 5.500,-;
\end{abstract}


b) Route 2 with a fare of IDR. 4,000,-; and c) Route 3 with a fare of IDR. $7,000,-$.

Keyword: Planning, Feeder Transport, Analysis.

\section{A. PENDAHULUAN}

Transportasi merupakan suatu sistem yang sangat penting dalam kehidupan sehari-hari, sistem transportasi menggunakan moda angkutan umum dapat mengembangkan dan memajukan suatu wilayah tersebut (Harijan, et al.,2012). Karena itu angkutan umum memegang peranan penting untuk menunjang aksesibilitas masyarakat dalam melakukan perjalanannya. Pelayanan angkutan umum diharapkan mampu menyediakan aksesibilitas yang baik bagi pengguna jasa angkutan umum (Syamshabrina \& Ariastita, 2017). Jasa pelayanan angkutan umum memiliki peran penting dalam mengakomodasi pergerakan masyarakat ke berbagai tujuan yang diperlukan untuk pemenuhan kebutuhan hidup masyarakat yang mempengaruhi kegiatan perekonomian suatu daerah (Hidayat \& Hardianto, 2018). Pertumbuhan dan perkembangan suatu daerah ditandai dengan peningkatan aktivitas dan mobiltas penduduknya, sehingga untuk mendukung seluruh kegiatan diperlukan sarana dan prasarana transportasi yang efektif dan efisien (Sriastuti, 2016). Hal tersebut menjadikan angkutan massal sebagai salah satu moda yang merupakan penggerak segala potensi yang ada di daerah.

Kecamatan Kuta Selatan merupakan salah satu kawasan pusat pariwisata dan perekonomian yang ada di Kabupaten badung. Menjadi tujuan perjalanan dari sebagian masyarakat di Bali maupun wisatawan mancanegara ataupun wisatawan domestik. Kawasan Kuta Selatan mengalami kemajuan pembagunan diberbagai sektor, kemacetan merupakan merupakan masalah utama dengan pesatnya pertumbuhan kendaraan bermotor, disebabkan meningkatnya jumlah kendaraan, juga disebabka oleh meningkatnya pola perjalanan (transport demand) seiring dengan meningkatnya pertumbuhan ekonomi, maka penyediaan angkutan publik yang memadai dapat memecahkan masalah kemacetan (Libania \& Herwening, 2014; Widiyanti, 2017). Pemerintah dengan masalah kemacetannya telah memberi solusi untuk mengatasinya yaitu dengan menyediakan angkutan massal Trans SARBAGITA sehingga diharapkan pengguna kendaraan pribadi beralih ke angkutan publik tersebut. Adanya angkutan massal juga diharapkan segera dapat memecahkan kebutuhan masyarakat akan angkutan murah, aman, nyaman, dan cepat dengan pelayanan yang prima.

Trans SARBAGITA saat ini beroperasi melayani 2 koridor dan masing - masing koridor memiliki trayek sebagai berikut: a) Koridor 1memiliki rute Kota - Garuda Wisnu Kencana dengan panjang trayek $24 \mathrm{~km}$; dan b) Koridor 2memiliki rute Batubulan - Nusa Dua dengan panjang trayek 34km; Tingkat penggunaan kendaraan pribadi di Provinsi Bali telah mencapai 94\% (Tim PKL Provinsi Bali 2019). Hal ini seringkali menyebabkan kesemrawutan tatanan dan pola lalulintas yang ada di jalan raya pada umumnya. Kurangnya minat masyarakat untuk menggunakan angkutan massal disebabkan karena masyarakat masih menomorsatukan penggunaan kendaraan pribadi seperti sepeda motor dan mobil pribadi untuk menunjang kegiatannya (Putra \& Tangkudung, 2018). Padahal jika ditinjau dari segi tarif, tentunya Trans SARBAGITA ini sudah termasuk angkutan umum yang murah. Tentunya secara kasat mata dapat simpulkan bahwa ada suatu kekurangan yang terjadi dalam pengoperasian Trans SARBAGITA ini sehingga membuat masyarakat enggan menggunakan Trans SARBAGITA untuk menunjang kegiatannya. Dalam artian sistem pelayanan yang diterapkan saat ini tidak membuat masyarakat tertarik untuk menomorsatukan angkutan umum terutama Trans SARBAGITA.

Hal ini dapat dilihat dari load factor Trans SARBAGITA pada koridor 2 sebesar $20 \%$ dan masih banyaknya masyarakat yang menggunakan angkutan pribadi menuju ke suatu 
zona yang dilalui jalur Trans SARBAGITA.

\section{B. TINJAUAN PUSTAKA}

\section{Anggkutan Umum}

Angkutan Umum adalah angkutan penumpang yang dilakukan dengan sistem sewa atau bayar. Termasuk dalam pengertian angkutan umum penumpang adalah angkutan kota (bus, minibus, dsb), kereta api, angkutan air dan angkutan udara (Rahma et al.,2014). Angkutan umum diselenggrakan dalam upaya memenuhi kebutuhan angkutan yang selamat, aman, nyaman, dan terjangkau.

Pemerintahlah yang bertanggung jawab atas penyelenggaraan angkutan umum. Penyediaan jasa angkutan umum dilaksanakan oleh badan usaha milik Negara, badan usaha milik daerah, dan/atau badan hukum lain sesuai dengan ketentuan peraturan perundangundangan (Ghlyats, 2019). Perusahaan angkutan umum wajib memenuhi standar pelayanan minimal yang meliputi: a) Keamanan; b) Keselamatan; c) Kenyamanan; d) Keterjangkauan; e) Kesetaraan; dan f) Keteraturan (Undang-Undang Nomor 22 Tahun 2009 tentang Lalu Lintas dan Angkutan Jalan).

\section{Bus Rapid Transit}

Banyak kota telah mengembangkan variasi tema tentang pelayanan bus yang lebih baik. Salah satunya adalah Bus Rapid Transit (BRT) yang merupakan sistem transportasi berbasis bus yang berkapasitas dan berkecepatan tinggi, serta memiliki kualitas layanan yang baik dengan biaya yang relatif murah (Afriyansyah, 2017). BRT juga mengombinasikan beberapa elemen seperti jalur khusus bus yang pada umumnya berada pada median jalan, penarikan tarif off -board, level boarding, prioritas bus pada persimpangan, dan elemen kualitas layanan lainnya (seperti teknologi informasi serta branding yang kuat), (Institute for Transportation and Development Policy, The BRT Standard, 2016). Sedangkan dalam Peraturan Menteri Nomor 15 Tahun 2019 tentang Penyelenggaraan Angkutan Orang dengan Kendaraan Bermotor Umum dalam Trayek, BRT disebutkan sebagai angkutan massal berbasis jalan dan merupakan satu kesatuan dalam pelayanan angkutan perkotaan (Purwanto \& Ismiyati, 2015). Berdasarkan peraturan tersebut angkutan massal berbasis jalan harus didukung: a) Mobil Bus yang berkapasitas angkut massal; b) lajur khusus; c) Trayek Angkutan umum lain yang tidak berimpitan; d) dengan Trayek Angkutan Massal; dan e) Angkutan pengumpan (Nashirudin \& Putra, 2019).

Angkutan Massal berbasis jalan sebagaimana dimaksuddapat diimplementasikan dandikembangkan melalui tahapan sesuai dengan kapasitas jaringan jalan, bangkitan dan tarikan perjalanan, serta rencana penyelenggaraan (Ferdiansyah, 2009). Tahap pengembangan Angkutan Massal berbasis jalansebagaimana terdiri atas: a) tahap implementasi awal Angkutan Massal berbasis jalan (pre bus rapid transit); b) tahap pengembangan Angkutan Massal berbasis jalan (semi bus rapid transit); dan c) tahap implementasi penuh Angkutan Massal berbasis jalan (full bus rapid transit) (Ansyah et al.,2021).

Pelayanan angkutan umum massal menggunakan mobil bus yang berkapasitas angkut massal sebagaimana mobil bus besar.Selain menggunakan mobil bus besar angkutan massal dapat menggunakan mobil bus maxi, mobil bus tingkat, mobil bus tempel, dan bus sedang.

\section{Jalan Trayek}

Trayek adalah lintasan kendaraan bermotor umum untuk pelayanan jasa angkutan orang dengan mobil penumpang atau mobil bus yang mempunyai asal dan tujuan perjalanan tetap, lintasan tetap, dan jenis kendaraan tetap serta berjadwal atau tidak berjadwal (Herdiana \& Firdaus, 2021). Sedang jaringan trayek adalah kumpulan trayek yang menjadi satu kesatuan pelayanan angkutan orang. 
Kumpulan trayek bus kota akan membentuk suatu jaringan dan mempunyai suatu pola tertentu. Pola jaringan trayek yang dapat dimplementasikan di Indonesiayaitu pola radial, pola grid, pola radial bersilang, pola jalur utama dengan feeder dan pola time transfer network.

a. Pola Radial

Pada pola radial, seluruh atau hampir seluruh jalur utama membentuk jari-jari dari pusat ke daerah pinggiran kota. Pelayanan trayek memotong pusat kota, memutar pusat kota atau berhenti di pusat kota.

b. Pola Orthogonal/grid

Pola Orthogonal/grid ditandai dengan lintasan-lintasan yang membentuk grid (kisi-kisi) sebagian menuju ke pusat kota dan sebagian lainnya tidak menuju pusat kota. Tujuan utama pola ini memberikan pelayanan yang sama untuk semua bagian kota.

c. Pola Radial Bersilang

Pola radial bersilang bertujuan untuk mempertahankan karakteristik pola grid dan tetap mendapatkan keuntungan pola radial dengan saling menyilangkan lintasan dan menyediakan titik-titik tambahan dimana lintasan saling bertemu seperti di pusat-pusat perbelanjaan atau di tempat pendidikan.

d. Pola Jalur Utama dengan Feeder

Feeder adalah jalan-jalan yang menuju jalur utama. Jalan arteri melayani koridor utama yang berbentuk linier atau memanjang karena kondisi topografi dan pola jaringan jalan, atau perkembangan kota berbentuk linier dan lain-lain. Untuk itu dipilih pelayanan jenis feeder berupa lintasan menuju jalan utama dari pada membuat lintasan angkutan kota sepanjang jalan untuk mencapai tujuan. Sedangkan keuntungannya dapat meningkatkan pelayanan jalur utama.

e. Pola Time Transfer Network

Untuk Pola Time Transfer Network perlu perencanaan sangat cermat, karena membutuhkan koordinasi antara perencanaan rute dan penjadwalan. Keuntungan pola ini adalah penumpang tidak perlu ke pusat kota untuk berpindah atau menunggu lama, karena seluruh lintasan melayani titik-titik perpindahan penumpang dengan frekuensi, jadwal kedatangan dan keberangkatan yang sama, sehingga angkutan kota dijadwalkan saling bertemu atau bersimpangan selama waktu tertentu untuk penumpang berpindah kendaraan.

\section{Feeder}

Secara definisi bahasa, feeder berarti pengumpan. Dalam hal keterkaitannya dengan sistem trunk line, feeder dan trunk line menjadi kesatuan sistem, di mana jalur atau daerah feeder menghubungkan daerah-daerah bangkitan perjalanan menuju koridor- koridor utama dan sebaliknya (Murtejo, 2020). Idealnya, jalur feeder tentu lebih pendek dibandingkan koridor utamanya. Secara prinsip moda yang digunakan sebagai angkutan feeder dapat berupa kereta api, bus (bus besar, bus sedang, dan bus kecil) serta kendaraan pribadi yang memanfaatkan sistem park and ride atau kiss and ride. Secara umum, tujuan dari pengembangan jalur pelayanan feeder adalah: a) Meningkatkan pemanfaatan kapasitas trunk line; b) Memperluas cakupan pelayanan trunk line; c) Meningkatkan kualitas pelayanan; d) Meningkatkan koordinasi pelayanan antar moda angkutan umum; e) Mendorong upaya efisiensi operasional pada perusahaan bus; dan f) Membuat sistem ongkos/tarif yang lebih efektif (Sitorus, 2013).

Dilihat dari sisi sistem jaringan, pengembangan jalur feeder ini dapat terdiri dari tiga bentuk sistem jaringan, yaitu: a) Sistem jalur feeder yang langsung menuju terminal utama (feeder to main busway terminal), dimana jalur feeder akan terhubung langsung dengan terminal bus yang juga merupakan terminal trunk line; b) Sistem jalur feeder penghubung (intermediate service), dimana jalur feeder hanya berpotongan dengan koridor utama. Dengan kondisi ini, penumpang dari jalur feeder harus menuju halte trunk line yang terdekat dengan jalur feeder tersebut; dan c) Sistem feeder yang menghubungkan kawasan potensial dengan titik-titik tertentu yang terhubung dengan trunk line (point to point service), di mana konsep ini 
berupaya untuk menciptakan suatu akses langsung dari suatu kawasan dengan potensi permintaan yang besar dengan trunk line terdekat.

\section{METODE}

Penelitian ini menggunakan jenis penelitian kualitatif dengan pendekatan analisis deskriptif. Data dalam penelitian ini berjenis data primer dan data sekunder. Data primer dalam penelitian ini yaitu data tingkat kebersediaan minat berpindah dari keadaan pribadi ke angkutan feeder. Selain itu, data sekunder dalam penelitian ini didapat dari instansi terkait yang sudah terlebih dahulu mengumpulkan data di lapangan. Instansi-instansi pemerintah tersebut adalah sebagai berikut: a) Badan Perencanaan Pembangunan Daerah (BAPPEDA) kabupaten Badung; b) Dinas Perhubungan Provinsi Bali; dan c) Data Laporan Pola Umum PKL Provinsi Bali tahun 2019. Data yang telah dikumpulkan lalu dilanjutkan untuk dilakukan analisa guna mendapatkan kondisi eksisting dari wilayah studi. Metode pengumpulan data dalam penelitian ini menggunakan metode survei, wawancara dan studi literatur (Hidayat \& Kushari, 2015). Metode analisis data dalam penelitian ini menggunakan metode analisis permintaan, analisis pemilihan rute, analisis armada, dan analisis BOK.

\section{HASIL DAN PEMBAHASAN}

\section{Analisis Permintaan}

Dalam penelitian ini, penulis mendapatkan sampel penelitian menggunakan teori Slovin, sedangkan teknik pengumpulan data dengan observasi, wawancara dan dokumentasi.Terdapat enam zona yang menjadi suatu populasi, penghitungan sampel wawancara pengunjung menggunakan rumus "SLOVIN" dengan standar deviasi 5\%, maka diperoleh perhitungan, sebagaimana dinyatakan pada tabel berikut:

Tabel 1. Jumlah Sampel Wawancara Pengunjung Hotel

\begin{tabular}{|c|c|c|c|}
\hline Zona & Kelurahan & $\begin{array}{c}\text { Jumlah } \\
\text { Pengunjung perhari }\end{array}$ & Sampel \\
\hline 1 & Pecatu & 156 & 112 \\
\hline 2 & Ungasan & 137 & 102 \\
\hline 3 & Kutuh & 124 & 95 \\
\hline 4 & Benoa & 212 & 139 \\
\hline 5 & Tanjung Benoa & 109 & 86 \\
\hline 6 & Jumbaran & 254 & 155 \\
\hline \multicolumn{2}{|r|}{ Total } & 1103 & 689 \\
\hline
\end{tabular}

Sumber: data diolah

Dari tabel diatas, diketahui bahwa jumlah sampel yang harus diambil dari seluruh zona yang menjadi objek penelitian adalah sebanyak 689 responden. Analisis perhitungan demand digunakan untuk mengetahui berapa jumlah armada yang dibutuhkan untuk beroperasi sehingga penyediaan angkutan feeder untuk melayani penumpang tidak terlalu sedikit yang menyebabkan penumpang terlantar dan juga terlalu banyak yang bisa menyebabkan kerugian. Analisis demand didapat dari survei wawancara yang dilakukan kepada pengunjung hotel di kawasan Kuta Selatan. Untuk demand yang berasal dari pengunjung dapat diketahui dari survei wawancara dimana rata-rata penumpang memberikan pernyataan setuju untuk beralih moda menuju angkutan feeder.

Pada gambar dibawah dapat diketahui bahwa dari total semua pengunjung terdapat sebanyak 55\% yang menyatakan ingin beralih moda menggunakan angkutan feeder. Matriks 
OD Permintaan Aktual dan Potensial Angkutan disajikan dalam tabel berikut:

Tabel 2. Matriks OD Perminataan Aktual dan Permintaan Potensial Angkutan Feeder

\begin{tabular}{|c|c|c|c|}
\hline OD/AKTUAL & Halte 1 (Zona 4) & Halte 2 (Zona 6) & TJ \\
\hline 1 & 0 & 12 & 12 \\
\hline 2 & 0 & 10 & 10 \\
\hline 3 & 11 & 0 & 11 \\
\hline 4 & 10 & 0 & 10 \\
\hline 5 & 9 & 0 & 9 \\
\hline 6 & 0 & 15 & 15 \\
\hline AJ & $\mathbf{3 0}$ & $\mathbf{3 6}$ & $\mathbf{6 6}$ \\
\hline OD/POTENSIAL & Halte 1 (Zona 4) & Halte 2 (Zona 6) & TJ \\
\hline 1 & 0 & 78 & 68 \\
\hline 2 & 0 & 66 & 77 \\
\hline 3 & 77 & 0 & 72 \\
\hline 4 & 72 & 0 & 65 \\
\hline 5 & 65 & 0 & 99 \\
\hline 6 & 0 & 99 & $\mathbf{4 5 8}$ \\
\hline AJ & $\mathbf{2 1 5}$ & $\mathbf{2 4 3}$ & \\
\hline
\end{tabular}

Sumber: data diolah

Berdasarakan matriks asal tujuan pengunjung menggunakan angkutan umum menunjukkan bahwa total permintaan penumpang aktual pada zona 4 sebanyak 30 orang dengan permintaan perjalanan tertinggi berasal dari zona 3 sebesar 11 orang. Kemudian di zona 6 total permintaan aktual sebanyak 36 orang dengan permintaan perjalanan tertinggi berasal dari zona 6 yang merupakan kawasan wisata dan pendidikan dengan permintaan 15 orang.

Pada tabel permintaan potensial diatas didapatkan dari pengunjung pengguna angkutan umum dijumlahkan dengan pengguna kendaraan pribadi yang berminat dan bersedia berpindah ke angkutan feeder. Pada zona 4 total permintaan potensial sebesar 215 orang dengan permintaan perjalanan tertinggi berasal dari zona 3. Selanjutnya pada zona 6 total permintaan potensial sebesar 243 orang dengan permintaan perjalanan tertinggi berasal dari zona 6 yang merupakan kawasan wisata dan pendidikan dengan permintaan 99 orang.

\section{Analisis Rencana Rute Angkutan Feeder}

Penentuan jenis armada angkutan feeder menggunakan kendaraan mobil penumpang umum dengan kapasitas 8 seat penumpang dengan asumsi bahwa kendaraan berdimensi kecil untuk menyesuaikan dengan karakteristik tata guna lahan dan kondisi jalan di Provinsi Bali.

Mobil penumpang umum ini sesuai dengan ketentuan Peraturan Menteri Nomor 29 Tahun 2015 Tentang Standar Pelayanan Minimal Angkutan Orang dengan Kendaraan Bermotor Umum dalam Trayek. Pada penyelenggaraan angkutan umum dalam perkotaan, kapasitas yang dimiliki adalah 8 seat. Sedangkan pada pengoperasiannya nanti, seat yang dioperasikan adalah 11 seat ( sesuai dengan kondisi eksisting dilapangan) dengan konfigurasi yang disediakan duduk dibelakang berhadap - hadapan sebanyak 10 seat (6 seat di bagian kanan supir dan 4 seat di bagian kiri supir) dan 1 seat di depan sebelah kiri pengemudi.

Selanjutnya, Hal utama yang dilakukan dalam menentukan design rute perencanaan pengoperasian angkutan feeder adalah dengan mempertimbangkan titik asal perjalanan dan titik tujuan perjalanan. Jarak antara titik asal dan titik tujuan tidak terlalu pendek, tidak terlalu panjang dan tidak bertele-tele. Hal itu harus diperhatikan agar jika nantinya perencanaan angkutan feeder ini direalisasikan tetap memegang prinsip dari pengoperasionalan diatas dengan memperhatikan jarak yang terdekat dan tidak terlepas dari peranannya sebgai angkutan 
penunjang Trans SARBAGITA.

Rute yang akan dilayani merupakan rute yang memiliki permintaan potensial perjalanan yaitu yang melalui titik hotel, tempat ibadah, pusat oleh-oleh/perbelanjaan, kampus Udayana. Sehingga akan membangkitkan permintaan perjalanan. Adapun usulan rute trayek angkutan feeder sebagai berikut:

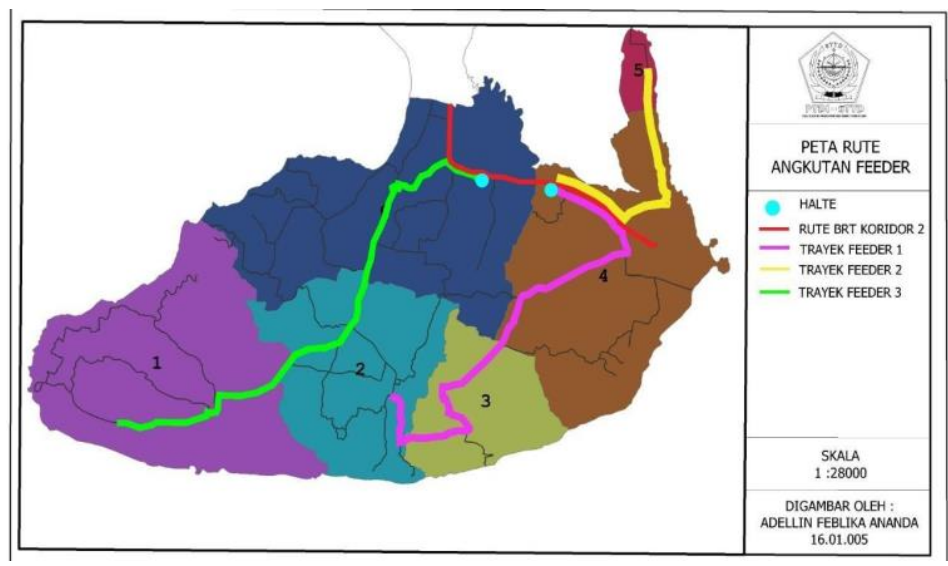

Gambar 2. Visualisasi Trayek

Sumber: data diolah

Berdasarkan gambar tersebut, dapat terlihat usulan rute angkutan feeder yang mengumpani BRT koridor 2.

Tabel 3. Usulan Rute Angkutan Feeder

\begin{tabular}{|c|c|c|}
\hline Trayek & Rute & Panjang Rute \\
\hline 1 & $\begin{array}{c}\text { Jl. Karang Pandawa-Jl. Alas Arum-Jl. } \\
\text { Raya Nusa Dua Selatan-Jl. Gapura Vista- } \\
\text { Jl. Gunung Payung-Jl. Dharmawangsa--Jl. } \\
\text { Kuruksetra-Jl. Siligita-Jl. By Pass Ngurah } \\
\text { Rai }\end{array}$ & $12 \mathrm{KM}$ \\
\hline 2 & Jl. Pratama-Jl. By Pass Ngurah Rai & $9 \mathrm{KM}$ \\
\hline 3 & $\begin{array}{c}\text { Jl. Raya Uluwatu Pecatu-Jl. Raya Kampus } \\
\text { Unud-Jl. By Pass Ngurah Rai }\end{array}$ & $15 \mathrm{KM}$ \\
\hline
\end{tabular}

Sumber: data diolah

Kinerja operasional Trayek 1, untuk mengetahui kesesuaian kinerja dengan standar yang ditetapkan, maka dilakukan analisis kinerja operasional terhadap jenis kendaraan yang direkomendasikan. Berikut adalah analisis kinerja operasional jenis kendaraan MPU, diketahui bahwa:

Titik A

Titik B

Kecepatan Rencana

Waktu Operasi

Panjang rute

$$
\begin{aligned}
& =\mathrm{j} 1 . \text { Karang Pandawa } \\
& =\mathrm{j} 1 . \text { By Pass Ngurah Rai, Benoa } \\
& =30 \mathrm{~km} / \mathrm{jam} \\
& =08.00-20.00 \\
& =12 \mathrm{~km}
\end{aligned}
$$




$\begin{array}{ll}\text { Waktu Tempuh } & =24 \text { menit } \\ \text { Faktor muat rencana } & =70 \% \\ \text { Jumlah penumpang per hari } & =149 \text { penumpang/hari } \\ \text { Jumlah kapasitas kendaraan } & =8 \text { penumpang }\end{array}$

Maka, rekapitulasi rencana kinerja operasional trayek 1 disajikan dalam tabel berikut:

Tabel 4. rekapitulasi rencana kinerja operasional trayek 1

\begin{tabular}{|c|c|c|c|c|c|c|}
\hline \multicolumn{7}{|c|}{ Rencana Operasi Angkutan Feeder } \\
\hline Kapasitas (penumpang) & \multicolumn{7}{|c|}{30} \\
\hline Panjang Rute (km) & \multicolumn{7}{|c|}{24} \\
\hline Kecepatan Operasi (km/jam) & \multicolumn{7}{|c|}{53} \\
\hline Travel Time (menit) & \multicolumn{7}{|c|}{} \\
\hline RTT (menit) & \multicolumn{7}{|c|}{30} \\
\hline Headway (menit) & 24 & 29 & 34 & 38 & 43 & 48 \\
\hline Load Factor & 50 & 60 & 70 & 80 & 90 & 100 \\
& $\%$ & $\%$ & $\%$ & $\%$ & $\%$ & $\%$ \\
\hline Frekuensi (kendaraan/jam) & 3 & 3 & 2 & 2 & 2 & 2 \\
\hline Jumlah Armada (unit) & 3 & 2 & 2 & 2 & 2 & 2 \\
\hline
\end{tabular}

Sumber: data diolah

Berdasarkan data pada tabel di atas diketahui bahwa pada rencana operasi jenis kendaraan MPU, jumlah armada yang dibutuhkan adalah sebanyak 2 armada dengan headway 34 menit.

Pada Analisis Kinerja Operasional Trayek 2, untuk mengetahui kesesuaian kinerja dengan standar yang ditetapkan, maka dilakukan analisis kinerja operasional terhadap jenis kendaraan yang direkomendasikan. Berikut adalah analisis kinerja operasional jenis kendaraan MPU, diketahui bahwa:

Titik A

$$
\begin{aligned}
& =\mathrm{J} 1 . \text { Pratama } \\
& =\mathrm{J} 1 . \text { By Pass Ngurah Rai, Benoa } \\
& =30 \mathrm{Km} / \mathrm{jam} \\
& =08.00-20.00 \\
& =9 \mathrm{Km} \\
& =18 \mathrm{menit} \\
& =70 \% \\
& =65 \text { penumpang/hari } \\
& =8 \text { penumpang }
\end{aligned}
$$

\begin{tabular}{|c|c|c|c|c|c|c|}
\hline \multicolumn{7}{|c|}{ Rencana Operasi Angkutan Feeder } \\
\hline Kapasitas (penumpang) & \multicolumn{6}{|c|}{8} \\
\hline Panjang Rute $(\mathrm{km})$ & \multicolumn{6}{|c|}{9} \\
\hline Kecepatan Operasi (km/jam) & \multicolumn{6}{|c|}{30} \\
\hline Travel Time (menit) & \multicolumn{6}{|c|}{18} \\
\hline RTT (menit) & \multicolumn{6}{|c|}{41} \\
\hline Headway (menit) & 55 & 66 & 77 & 88 & 99 & 110 \\
\hline Load Factor & $\begin{array}{l}50 \\
\% \\
\end{array}$ & $\begin{array}{l}60 \\
\% \\
\end{array}$ & $\begin{array}{l}70 \\
\% \\
\end{array}$ & $\begin{array}{l}80 \\
\% \\
\end{array}$ & $\begin{array}{l}90 \\
\%\end{array}$ & $\begin{array}{c}100 \\
\% \\
\end{array}$ \\
\hline Frekuensi (kendaraan/jam) & 2 & 1 & 1 & 1 & 1 & 1 \\
\hline
\end{tabular}$$
\text { Faktor muat rencana }
$$

Jumlah kapasitas kendaraan

Maka, rekapitulasi rencana kinerja operasional trayek 2 disajikan dalam tabel berikut:

Tabel 5. rekapitulasi rencana kinerja operasional trayek 2 


\begin{tabular}{|c|c|c|c|c|c|c|}
\hline Jumlah Armada (unit) & 1 & 1 & 1 & 1 & 1 & 1 \\
\hline
\end{tabular}

Sumber: data diolah

Berdasarkan data pada table di atas diketahui bahwa pada rencana operasi jenis kendaraan MPU, jumlah armada yang dibutuhkan adalah sebanyak 1 armada dengan headway 77 menit.

Selanjutnya, untuk Kinerja Operasional Trayek 3 guna mengetahui kesesuaian kinerja dengan standar yang ditetapkan, maka dilakukan analisis kinerja operasional terhadap jenis kendaraan yang direkomendasikan. Berikut adalah analisis kinerja operasional jenis kendaraan MPU, diketahui bahwa:

Titik A

Titik B

Kecepatan Rencana

Waktu Operasi

Panjang rute

Waktu Tempuh

Faktor muat rencana

Jumlah penumpang per hari

Jumlah kapasitas kendaraan

$$
\begin{aligned}
& =\mathrm{j} 1 . \text { Raya Uluwatu Pecatu } \\
& =\mathrm{j} 1 . \text { By Pass Ngurah Rai, Jimbaran } \\
& =30 \mathrm{~km} / \mathrm{jam} \\
& =08.00-20.00 \\
& =15 \mathrm{~km} \\
& =30 \mathrm{menit} \\
& =70 \% \\
& =243 \text { penumpang/hari } \\
& =8 \text { penumpang }
\end{aligned}
$$

\begin{tabular}{|c|c|c|c|c|c|c|}
\hline \multicolumn{7}{|c|}{ Rencana Operasi Angkutan Feeder } \\
\hline Kapasitas (penumpang) & \multicolumn{6}{|c|}{8} \\
\hline Panjang Rute (km) & \multicolumn{6}{|c|}{15} \\
\hline Kecepatan Operasi (km/jam) & \multicolumn{6}{|c|}{30} \\
\hline Travel Time (menit) & \multicolumn{6}{|c|}{30} \\
\hline RTT (menit) & \multicolumn{6}{|c|}{69} \\
\hline Headway (menit) & 15 & 18 & 21 & 24 & 27 & 29 \\
\hline Load Factor & $\begin{array}{l}50 \\
\%\end{array}$ & $\begin{array}{l}60 \\
\%\end{array}$ & $\begin{array}{l}70 \\
\%\end{array}$ & $\begin{array}{l}80 \\
\%\end{array}$ & $\begin{array}{l}90 \\
\%\end{array}$ & $\begin{array}{c}100 \\
\%\end{array}$ \\
\hline Frekuensi (kendaraan/jam) & 5 & 3 & 3 & 3 & 3 & 3 \\
\hline Jumlah Armada (unit) & 5 & 5 & 4 & 4 & 3 & 3 \\
\hline
\end{tabular}

Maka, rekapitulasi rencana kinerja operasional trayek 3 disajikan dalam tabel berikut:

Tabel 6. Rekapitulasi Rencana Kinerja Operasional Trayek 3

Sumber: data diolah

Berdasarkan data pada table di atas diketahui bahwa pada rencana operasi jenis kendaraan MPU, jumlah armada yang dibutuhkan adalah sebanyak 3 armada dengan headway 21 menit.

\section{Analisis Biaya Operasional Kendaraan dan Tarif}

BOK ini bertujuan untuk menghitung biaya yang dikeluarkan oleh operator dalam memproduksi jasa angkutan dalam seat per $\mathrm{km}$. Dalam perhitungan BOK diperlukan data-data mengenai harga komponen dari kendaraan yang berlaku saat ini, data-data ini didapat penulis dari hasil analisis terhadap biaya komponen kendaraan yang berlaku. Terdapat biaya tamabahan seperti biaya asuransi, biaya awak kendaraan, biaya KIR, biaya STNK, biaya pegawai kantor, dan biaya izin usaha. Maka selanjutnya dihitung seberapa besarnya biaya operasi kendaraan yang dikeluarkan untuk mengoperasikan satu kendaraan dalam satu tahun. Untuk lebih jelasnya dapat dilihat perhitungan BOK di bawah ini:

Tabel 7. Produksi Angkutan Feeder

\begin{tabular}{|r|l|c|c|}
\hline No & \multicolumn{1}{|c|}{ Keterangan } & Nilai & Satuan \\
\hline 1 & Panjang Trayek & 12.00 & $\mathrm{Km}$ \\
\hline
\end{tabular}




\begin{tabular}{|r|l|c|c|}
\hline 2 & Km-tempuh/rit & 24.00 & $\mathrm{Km}$ \\
\hline 3 & Frekuensi/hari & 13 & rit \\
\hline 4 & Km tempuh/hari & 312 & $\mathrm{Km}$ \\
\hline 5 & Hari operasi/bulan & 30 & hari \\
\hline 6 & Hari operasi/tahun & 360 & hari \\
\hline 7 & Km tempuh/bulan & 9360.0 & $\mathrm{Km}$ \\
\hline 8 & Km tempuh/tahun & 112,320 & $\mathrm{Km}$ \\
\hline 9 & Seat.km per rit & 192 & seat.Km \\
\hline 10 & seat.km per hari & 2,496 & seat. $\mathrm{Km}$ \\
\hline 11 & seat.km per bulan & 74,880 & seat.Km \\
\hline 12 & seat.km per tahun (PST) & 898,560 & seat.Km \\
\hline
\end{tabular}

Sumber: data diolah

Biaya pokok dihitung sebelum memasukkan besarnya keuntungan yang wajar bagi operator. Jadi besarnya biaya pokok untuk tiap kendaraan untuk BOK per bus km adalah:

Tabel 8. Besaran Biaya pokok untuk setiap kendaraan

\begin{tabular}{|c|c|}
\hline Rute & BOK per pnp/km \\
\hline Rute 1 & Rp 319,-- \\
\hline Rute 2 & Rp 321,-- \\
\hline Rute 3 & Rp. 324,-- \\
\hline
\end{tabular}

Sumber: data diolah

Biaya pokok per penumpang dihitung setelah memasukkan besarnya keutungan (margin) yang wajar bagi operator. Basarnya keutungan yang wajar adalah sebesar $10 \%$ dari biaya operasi yang dikeluarkan. Besarnya biaya pokok/penumpang adalah biaya pokok/kend/tahun dibandingkan dengan load factor 70\% dikalikan dengan kapasitas kendaraan.

Tarif Penumpang $=(\mathrm{BOK} /$ penumpang $\mathrm{x} 10 \%)+(\mathrm{BOK} /$ penumpang $\mathrm{x} \mathrm{Km}$ tempuh $)$

Contoh:

Perhitungan tarif berdasarkan BOK pada rute 1

Tarif/Penumpang $=($ Rp.456.09 x 10\% $)+($ Rp. $456.09 \times 12 \mathrm{~km})$

Tarif/Penumpang $=$ Rp. 5.519,-

Tabel 9. Tarif penumpang tiap rute

\begin{tabular}{|c|c|c|}
\hline Rute & Tarif Penumpang & Tarif Usulan \\
\hline Rute 1 & Rp. 5.519,- & Rp. 5.500 \\
\hline Rute 2 & Rp. 4.181,- & Rp. 4.000 \\
\hline Rute 3 & Rp. 6.992,- & Rp. 7.000 \\
\hline
\end{tabular}

Sumber: data diolah

Pada Tabel V.25 dapat dilihat hasil perhitungan tarif untuk rute 1, rute 2 dan rute 3 dimana tarif yang diusulkan untuk angkutan feeder rute 1 adalah Rp. 5.500, tarif rute 2 adalah Rp. 4.000 dan tarif rute 3 adalah Rp. 7.000.

\section{E. KESIMPULAN}

Berdasarkan analisis data dalam penelitian, maka dapat disimpulkan bahwa: 1) Berdasarkan hasil survei wawancara, diketahui bahwa jumlah permintaan untuk angkutan feeder adalah 66 responden untuk permintaan aktual dan 458 untuk permintaan potensial. Pergerakan yang ditimbulkan oleh responden yang paling tinggi berasal dari zona 6 , dimana tata guna lahan pada zona tersebut merupakan kawasan wisata dan pusat pendidikan; 2) Rute 
rencana untuk pengoperasian angkutan feeder di Kuta Selatan dibagi menjadi 3 rute dengan pelayanan rute yang berbeda; 3) Jumlah armada yang dibutuhkan pada tiap rute: Permintaan Potensial yaitu: a) Rute 1 jumlah kebutuhan armada 2 kendaraan, b) Rute 2 jumlah kebutuhan armada 1 kendaraan, dan c) Rute 3 jumlah kebutuhan armada 4 kendaraan; dan 4) Tarif usulan yang sesuai untuk angkutan feeder: a) Rute 1 dengan tarif sebesar Rp. 5.500,-; b) Rute 2 dengan tarif sebesar Rp. 4.000,-; dan c) Rute 3 dengan tarif sebesar Rp. 7.000,-.

\section{DAFTAR PUSTAKA}

Afriyanah, S. R. (2017). Kajian Model Pemilihan Moda Kereta Api Atau Bus Menuju Stasiun Kereta Api Kroya Dan Maos Di Kabupaten Cilacap. Jurnal Penelitian Transportasi Darat, 19(3), 183-194.

Ansyah, F., Buchari, E., \& Kadarsah, E. (2020). Analisis Perencanaan Tarif Kapal Bus Air Wisata Dalam Mewujudkan Konektivitas Angkutan di Kota Palembang. Jurnal Transportasi Multimoda, 17(2).

Ferdiansyah, R. (2009). Kemungkinan peralihan penggunaan moda angkutan pribadi ke moda angkutan umum perjalanan Depok-Jakarta. Jurnal Perencanaan Wilayah dan Kota, 20(3), 183-198.

Ghlyats Afif, S. (2019). Pentahapan Pengembangan Koridor Feeder Ix-Xii Brt Kota Semarang (Doctoral dissertation, POLITEKNIK TRANSPORTASI DARAT INDONESIA-STTD).

Harijan, H., Ismiyati, I., \& Narayudha, M. (2012). Evaluasi Dan Perencanaan Sistem Feeder Jalan Prof. Soedarto, Sh Tembalang, Semarang. Jurnal Karya Teknik Sipil, 1(1), 1-10.

Herdiana, S., \& Firdaus, M. S. (2020). Identifikasi Ketersediaan dan Kesesuaian Feeder di Kawasan Pemukiman Bandung Timur (Studi Kasus SWK Gedebage dan SWK Kordon). REKALOKA Jurnal Perencanaan Wilayah dan Kota, 1(1), 23.

Hidayat, A. M., \& Kushari, B. (2015). Kemauan Membayar (Willingness To Pay) Calon Penumpang Terhadap Rencana Pelayanan Transjogja Rute YogyakartaKaliurang. Teknisia, 20(1), 67-77.

Hidayat, B., Sudriyanto, E., \& Hardianto, D. (2018). Perencanaan Angkutan Pengumpan Lrt Dan Trans Jabodetabek Di Bekasi. Jurnal Penelitian Sekolah Tinggi Transportasi Darat, 9(1), 54-65.

Libania, R., \& Herwening, M. (2014). Evaluasi Kinerja Layanan Angkatan Umum Sebagai Feeder Kereta Api Bandara Di Stasiun Tanah Abang Jakarta. Warta Penelitian Perhubungan, 26(7), 373-380.

Murtejo, T. (2020). Kajian Rerouting Trayek Angkutan Umum Perkotaan: Studi Kasus di Kota Bogor. PROSIDING LPPM UIKA BOGOR.

Nashiruddin, M. R., \& Putra, K. H. (2019, August). Evaluasi Dan Perencanaan Sistem Feeder Jalan Pada Ruas Jalan Raya Wonokromo Surabaya Guna Meminimalisir Masalah 
Kemacetan. In Prosiding Seminar Teknologi Perencanaan, Perancangan, Lingkungan dan Infrastruktur (Vol. 1, No. 1, pp. 97-102).

Paramayudha, B. S., \& Handayeni, K. D. M. E. (2020). Studi Preferensi Konsep Integrasi Angkutan Feeder Suroboyo Bus Rute Purabaya-Rajawali dengan Metode Conjoint. Jurnal Teknik ITS, 9(1), E1-E6.

Purwanto, D., \& Ismiyati, I. (2015). Pengelolaan Transportasi Berwawasan Lingkungan Sebagai Dampak Perkembangan Perkotaan Tak Terkendali (Studi Kasus Kota Semarang). Media Komunikasi Teknik Sipil, 20(1), 93-101.

Putra, A. K., \& Tangkudung, E. S. (2018). Evaluasi Kinerja Layanan Angkutan Pengumpan Dalam Kota (City Feeder) Bus Transjakarta Rute Lebak Bulus-Senen. In Prosiding Forum Studi Transportasi antar Perguruan Tinggi.

Putra, A. K., \& Tangkudung, E. S. (2018). Evaluasi kinerja layanan angkutan pengumpan bus transjakarta rute Lebak Bulus-Senen. Jurnal Transportasi, 18(1), 29-38.

Rahma, S., Wijayanti, D. A., Ismiyati, I., \& Purwanto, D. (2014). Penyediaan Transportasi Umum Masa Depan di Kota Semarang. Jurnal Karya Teknik Sipil, 3(1), 154-166.

Sitorus, B. (2013). Kajian Pembenahan Angkutan Masal Untuk Mengurangi Kemacetan Lalu Lintas di DKI Jakarta. Warta Penelitian Perhubungan, 25(3), 177-186.

Sriastuti, N. (2016). Evaluasi Kinerja Pengoperasian Angkutan Pengumpan (Feeder) Trans Sarbagita Tp 02 Kota Denpasar. PADURAKSA: Jurnal Teknik Sipil Universitas Warmadewa, 5(1), 1-9.

Syamshabrina, A., \& Ariastita, P. G. (2017). Preferensi Pemerintah dan Badan Usaha dalam Pengembangan Lyn sebagai Angkutan Umum Feeder Di Surabaya Melalui Skema Kerjasma Pemerintah dan Badan Usaha (Studi Kasus: Angkutan Lyn Rute S dan Rute G Surabaya). Jurnal Teknik ITS, 6(2), E59-E62.

Widiyanti, D. (2017). Pengembangan Feeder Transportasi Massal Di Kota Medan. Jurnal Transportasi Multimoda, 13(3), 107-120.

Wulan, D. S. A., Sulistyono, S., \& Nurtanto, D. (2017). Feeder Route Planning Of Public Transportation In Jember. Jurnal Rekayasa Sipil dan Lingkungan, 1(01), 73-83. 